monte Esquilino, y les presenta el plano del templo dibujado con nieve ${ }^{10}$. El Papa tuvo el mismo sueño y organizó una expedición al monte para comprobar el milagro. Es la procesión a la izquierda del cobre, en perspectiva aérea. La nieve cubre el espacio consagrado al futuro templo, a pesar de estar en verano. En el lienzo de Murillo aparece el Niño en brazos de la Virgen, pero en el cobre figura sola, pero aparece con el Niño en una secuencia posterior, en la lejanía del cielo, fundida entre las nubes, amparando a la multitud. Recordamos que en la iglesia madre, en Santa María la Mayor de Roma, se reproduce un mosaico de 1300 con la misma historia del sueño del patricio y fundación de la iglesia. La Virgen esta sola y señala desde lo alto el lugar de la edificación, igual que en el cobre. Murillo lo hace con el Niño en los brazos y los esposos durmiendo entre cojines. Es una licencia más estética la del pintor sevillano, pues las fuentes antiguas los sitúan en la cama.

Murillo representa a la esposa dormida, mientras que en el mosaico medieval - como en el cobre - está sentada y velando el sueño de su esposo. También es'un escenario suntuoso el del mosaico. Todo esto coincide con el cobre del pintor flamenco. Advertimos que la aparición de la Virgen con el Niño a los esposos, contrariamente al mosaico y al cobre- aparece en el texto del Padre Croisset. Esta debió ser la fuente directa de Murillo. No sería extraño que existiera un grabado que sirviera a ambos maestros por igual. A pesar de la presencia o ausencia del Niño en brazos de la Virgen, el esquema compositivo está trazado con igual sintonía.

Es de interés recordar que el sueño es un motivo escaso en la pintura religiosa. Murillo representa al patricio con laxitud, elegante abandono del cuerpo, y rostro bello y apacible; mientras que Willem van Herp utiliza un personaje más directo y realista, en una instantánea algo procaz, aunque sin llegar a la vulgaridad. Resulta simpático este rostro en sombra contrastada. A título de sugerencia, nos recuerda, por sus mejillas llenas y mostachos apuntados hacia arriba, a la fisonomía de Jacob Jordaens en autorretratos de sus últimos años, como el que procede de la colección del barón G. Th. A. M. van Brienen de Grootelindt en Amsterdam [Fig. 4] ${ }^{11}$, grabado por Pieter de Jode y y J. Meyssens [Fig. 5] ${ }^{12}$.

Matías DíAz PAdrón

\title{
UN PRIMER RETABLO DE ALBERTO DE CHURRIGUERA
}

Es conocida en lo esencial la actividad desarrollada por Alberto de Churriguera en Salamanca durante su etapa de madurez, como maestro de la Catedral y de la Plaza Mayor y al frente de las obras de los Colegios de Cuenca, de San Bartolomé o del Rey entre otros, así como diversos trabajos en Valladolid, Madrid, Orgaz y otros lugares '. Sin embargo, son muy escasas las noti-

\footnotetext{
10 «Como la visión se había hecho a los dos, no dudaron que fuere legítima y sobrenatual. No obstante, se la comunicaron al Papa Liberio, el cual había tenido otra en todo semejante la misma noche; y viendo que el cielo se explicaba, quiso el Pontífice verificar el hecho con sus propios ojos. Mandó juntar el clero, y acompannado el Patricio Juan de su mujer y de todo el piadoso pueblo, fue procesionalmente al sitio donde se había anunciado la maravilla. Llegaron al monte esquilino, y en él se halló un espacio todo cubierto de nieve, sin embargo de ser en la fuerza del estío y en el mayor rigor de los calores» [Croisset, Año cristiano]. Vid. Angulo, Op. Cit. 1981, I, pp. 326-327.

$"$ Vendida en Christie's Londres, 8-XII-1961, No. 177.

12 Hollstein, F.W.H., Eaux-fortes, estampes et gravures hollandaises et flamandes, 1450-1700, Amsterdam, $1949,24$.

' García Bellido, Antonio, «Estudios del Barroco español. Avance para una monografía de los Churriguera», en Archivo Español de Arte y Arqueología, T. V (1929), pp. 70-73 y «Estudios del Barroco español. Avance para una monografía de
}

AEA, LXXVI, 2003, 301, pp. 79 a 93 
cias que tenemos de obras o encargos al comienzo de su carrera profesional, lo que proporciona interés a cualquier dato que pueda ofrecer más luz sobre su dedicación en esos primeros años.

Como se sabe Alberto de Churriguera había nacido en Madrid el 7 de agosto de 1676. A la muerte de sus padres quedó al cuidado de su hermano José, que se ocupó de formarlo y transmitirle su misma profesión «con toda eficacia» ${ }^{2}$. Se supone que en 1692 acompañó a su hermano a Salamanca para ejecutar el retablo de San Esteban, donde completaría su aprendizaje. De hecho unos años después aparece trabajando con él en las obras del colegio de San Agustín de esta ciudad, y tanto uno como otro extendían los recibos de gastos, como expresamente señala José de Churriguera en enero de $1698^{3}$, lo que indica una colaboración estrecha.

No obstante, por estas fechas Alberto de Churriguera debía haber alcanzado ya la maestría $\mathrm{y}$, si bien sigue manteniendo una vinculación con su hermano, al mismo tiempo comienza a desarrollar una actividad independiente. Así lo demuestra una escritura de obligación otorgada en solitario el 3 de abril de 1698 por la que se compromete, en calidad de «maestro de arquitectura», a ejecutar el retablo mayor de la ermita de Nuestra Señora de Gracia perteneciente a Pedrosillo el Ralo, un pueblo a catorce kilómetros de la capital charra en la que por entonces estaba avecindado Alberto Churriguera, así como un marco para el frontal del altar ${ }^{4}$. El nuevo retablo y el marco debían tallarse en buena madera de pino y estar terminados en julio de ese año, momento en que se le abonaría el tercer pago de los 1.800 reales en que se ajustó la obra.

El retablo no era muy grande. Según lo contratado debía medir diecinueve pies y medio de alto por catorce de ancho (unos 5,40 metros por 3,90), y no llegaba a cubrir todo el testero de la ermita, al abrirse en los extremos las puertas que conducían a la sacristía y al camarín. La realización del nuevo retablo debió plantearse a raíz de que en 1692 se reconstruyese la cabecera: un simple recinto cuadrangular de unos ocho metros de lado (entre 27 y 30 pies), iluminado con dos ventanas y comunicado con el cuerpo por un arco de cantería apoyado en dos machones ${ }^{5}$.

La escritura omite mayores detalles al remitir a una traza, pero ofrece interés el fiador. Figura como tal José Manrique de Larra ${ }^{6}$, maestro de escultura y vecino también de Salamanca, lo que supone que este artista, cuñado y colaborador habitual de los Churriguera, les siguió a esta ciudad mucho antes de lo que se pensó, quizá desde 1695. Faltan, sin embargo, referencias a cualquier trabajo escultórico, al margen de los habituales motivos ornamentales inherentes a la estructura arquitectónica, que pudiera hacer pensar también en su intervención. Lo más probable es que se reaprovechasen las imágenes existentes para flanquear a Nuestra Señora de Gracia, en concreto un San Antonio Abad que según un inventario de 1716 estaba colocado en el lado derecho y un San Sebastián mártir, dispuesto en la calle de la izquierda. Quizá lo único

los Churriguera. Nuevas aportaciones», en A.E.A.A., T. VI (1930), pp. 157-175. Rodríguez G. de Ceballos, Alfonso, Los Churriguera. Madrid, 1971. Del mismo autor, La Plaza Mayor de Salamanca. Salamanca, 1991. Castro Santamaría, Ana y Rupérez Almajano, Nieves, Monumentos salmantinos desaparecidos. El Colegio de Cuenca. Salamanca, Diputación, 1993 pp. 53 y ss.; Tovar Martín, Virginia, «El Colegio de la Orden Militar de Santiago, en Salamanca», en A.E.A, núm. 196 (1976), pp. 426-427. Verdú Ruiz, Matilde, «Nuevos datos sobre Alberto de Churriguera y su obra en Madrid: el retablo de la capilla mayor del convento de San Benito Magno. Herencia de la biblioteca del arquitecto Rodrigo Carrasco», en Anales del Instituto de Estudios Madrileños, tomo XXXVI, 1996, pp. 153-162.

${ }^{2}$ Rodríguez G. de Ceballos, Alfonso, «Nuevos documentos sobre José de Churriguera (1655-1700)», A.E.A., núm. 229 (1985), pp. 10-16. Diversos documentos de esta curaduría transcritos en Castañeda Becerra, Ana Mª, «Documentación sobre José de Churriguera y sus hermanos Joaquín y Alberto hallada en el Archivo Histórico de protocolos de Madrid», en Cuadernos de Iconografía, T. I, 1988, pp. 295-312.

${ }^{3}$ A.H.N., Clero, leg. 5715. Rupérez Almajano, N., «José de Churriguera en Salamanca (1692-1699)», en Anuario del Departamento de Historia y Teoría del Arte. Universidad Autónoma de Madrid. vol. IX-X, 1997-98, pág. 215.

${ }^{4}$ Archivo Histórico Provincial de Salamanca (A.H.P.S.), Prot. 3800, ff. 415r.-416r.

5 A.H.P.S., Prot. 3300, ff. 673-674. Se trataba de una obra de mampostería, con las esquinas, cornisa y ventanas de sillería.

${ }^{6}$ La primera vez que se había documentado en Salamanca es en 1701, contratando un tornavoz para la iglesia de San Pedro de Ávila junto a Joaquín de Churriguera. Rupérez Almajano, Nieves, «Aportaciones a la obra de Joaquín de Churriguera», en Boletín del Museo e Instituto "Camón Aznar», tomo LXV (1996), pág. 22. Una completa monografía en Rodríguez G. de Ceballos, Alfonso, «El escultor José de Larra Domínguez, cuñado de los Churriguera», en A.E.A., núm. 233, 1986 , pp. 1-32.

AEA, LXXVI, 2003, 301, pp. 79 a 93 

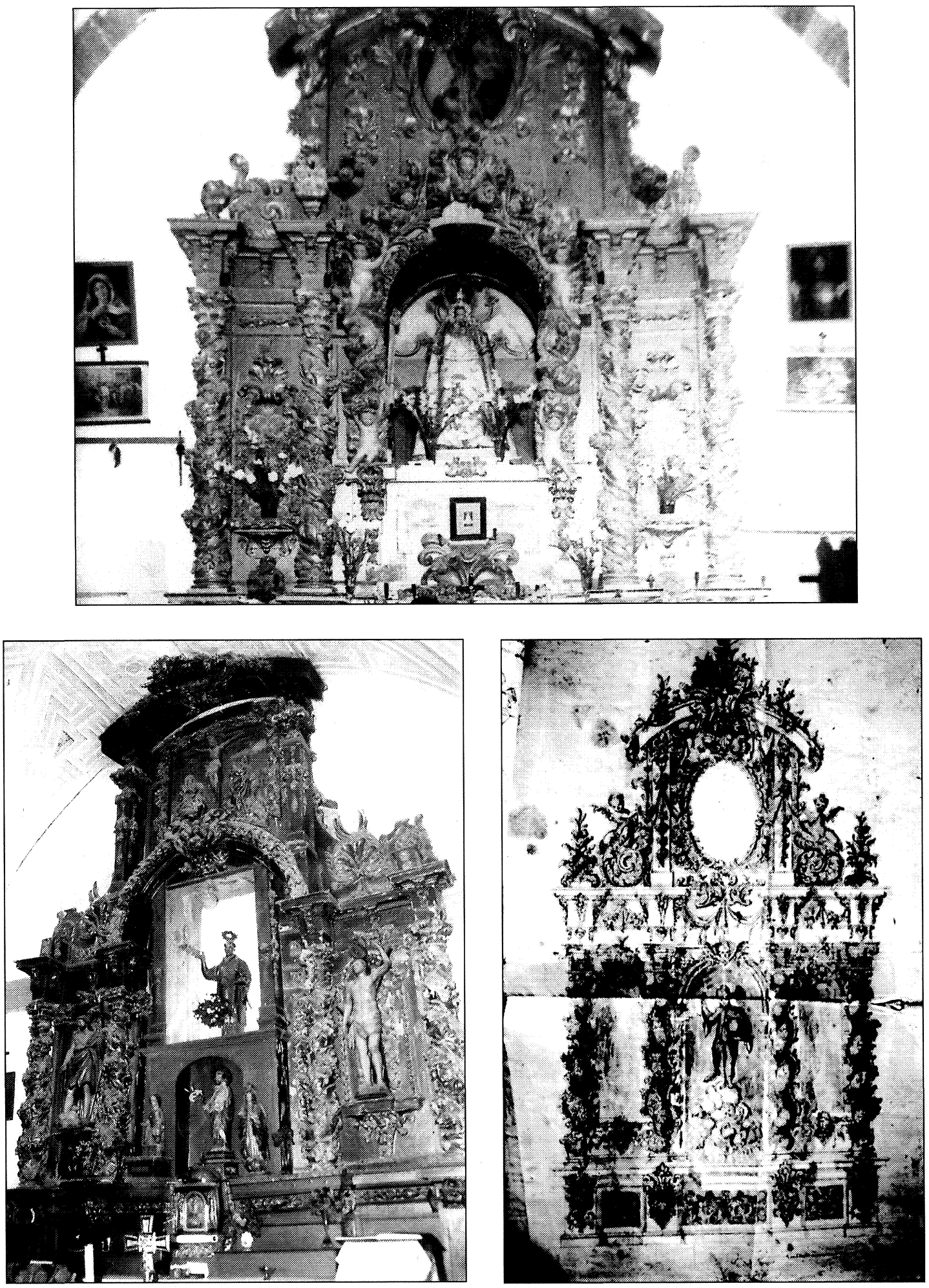

Fig. 1. Alberto de Churriguera: Retablo de la ermita de Nuestra Señora de Gracia. Pedrosillo el Ralo. 1698. Actualmente desaparecido.

Fig. 2. José de Churriguera: Retablo mayor de la iglesia de Carbajosa de la Armuña. 1698.

Fig. 3. Joaquín de Churriguera: Traza para dos retablos colaterales de la iglesia de Pedrosillo el Ralo. 1705.

AEA, LXXVI, 2003, 301, pp. 79 a 93 
que se hizo para la ocasión fue la pintura oval de San Gregorio Ostiense que ocupaba el ático, aunque la pérdida del libro de la cofradía correspondiente a estos años impide comprobarlo. Consta sin embargo que el retablo estaba ya perfectamente terminado y cumplida la obligación en octubre de 1700 , en que el obispo ordena su dorado ${ }^{7}$.

El resultado debió satisfacer al mayordomo Juan Martín, pues en septiembre de este año él mismo volvía a encargar a un Churriguera otros dos retablos para la iglesia de Pedrosillo ${ }^{8}$. Sin embargo, el hecho de que recurra en esta ocasión a Joaquín permite suponer que Alberto se había marchado a Madrid junto con su hermano José en 1699, lo que confirman otras fuentes ${ }^{9}$.

La ermita está actualmente abandonada y el retablo desapareció hace unos años fruto de la rapiña. No obstante, podemos conocer sus características gracias a una fotografía de los años setenta ${ }^{10}$ (fig. 1). El diseño es todavía deudor de la influencia ejercida por el mayor de los Churriguera, aunque años más tarde Alberto se atreva a competir con él. Responde en sus líneas generales al retablo contratado por José de Churriguera para el cercano pueblo de Carbajosa de la Armuña en octubre de 1698 (fig. 2) y a los retablos laterales que realiza su hermano Joaquín en 1705 para el mismo pueblo de Pedrosillo (fig. 3), lo cual no es extraño pues en los talleres solían existir modelos que se adaptaban a cada caso, como señala expresamente en cierta ocasión Pedro de Gamboa ${ }^{11}$. Como éstos constaba de un cuerpo tetrástilo de columnas salomónicas, profusamente ornamentadas con racimos y sarmientos, y un ático cerrado por un segmento de arco donde todavía se veía la pintura de San Gregorio. La calle central, mucho más amplia que las laterales, estaba ocupada por una profunda hornacina que comunicaba con el camarín, rodeada por una abultada decoración a base de motivos vegetales mezclados con simétricos angelitos de tosca talla y cabezas de querubín, que si bien no llegaba a enmascarar el trazado del arco de medio punto establecía una continuidad con el ático acentuando la verticalidad. La hojarasca cubría también con cierta profusión las ménsulas y los paneles del banco, las calles laterales, las volutas y el ático.

El esquema vuelve a aplicarse con pequeñas variantes y un incremento de las proporciones y precio en el retablo mayor de la iglesia de Los Santos, contratado el mismo año de 1698 y concluido antes de junio del siguiente. Aunque el libro de fábrica omite el nombre del artífice es probable que su realización se deba también a Alberto de Churriguera. Aparte de sus rasgos formales, permite suponerlo el hecho de que para hacer el remate acudió a los Santos un comisario de Pedrosillo, donde precisamente estaba trabajando aquél, y poco después se hicieron viajes a este pueblo y a Salamanca para ver al maestro que lo ejecutaba ${ }^{12}$.

Habrá que esperar más de veinticinco años para que Alberto de Churriguera vuelva de nuevo a esta ciudad, donde toma el relevo de su hermano Joaquín al frente de las principales obras arquitectónicas.

M. ${ }^{a}$ Nieves Rupérez Almajano Universidad de Salamanca

\footnotetext{
7 Archivo Diocesano de Salamanca (A.D.S.), libro de fábrica 296/12, fol. 118r.

${ }^{8}$ Rupérez Almajano, N., «Aportaciones a la obra...», pp. 20-21. De nuevo recurre a Joaquín en 1705 para otros retablos, iniciándose un largo pleito como consecuencia de las mejoras introducidas por él (Cf. Portal Monge, Yolanda, «Una traza de Churriguera», en Estudios Históricos Salmantinos. Homenaje al padre Benigno Hernández, Universidad de Salamanca, 1999, pp. 169-178).

${ }^{9}$ Consta su presencia en Madrid en junio de 1700 como testigo del segundo matrimonio de José Benito.

${ }^{10}$ Pertenece a doña Purificación Ruiz, a quien agradecemos las facilidades para su estudio y utilización.

"Este maestro colabora con Joaquín de Churriguera en la ejecución de varios retablos. Al contratar la obra del altar mayor de Machacón señala que la traza presentada tenía otras firmas porque había hecho otros retablos por ella. A.H.P.S., Prot. 5033, fol. 705 .

12 A.D.S., libro 342/21, ff. 87r. y v., 89v., 91r. Libro 342/32, fol. 59r. El coste de este retablo superó los seis mil reales, y en parte fue sufragado con fondos de la ermita de Nuestra Señora del Gozo.
}

$A E A$, LXXVI, 2003, 301, pp. 79 a 93 